\title{
Mitomycin, ifosfamide, cisplatin for non-small cell lung cancer: an implementation study
}

\author{
T. Berghmans ${ }^{1}$, A-P Meert1' V. Ninane'2, J-P Sculier ${ }^{1}$
}

ABSTRACT: Mitomycin, ifosfamide, cisplatin for nonsmall cell lung cancer: an implementation study. $T$. Berghmans, A-P Meert, V. Ninane, J-P Sculier.

Background. The MIP regimen (mitomycin, ifosfamide, cisplatin) demonstrated its effectiveness as firstline chemotherapy in phase II and III trials in NSCLC. We aimed to determine whether these results could be confirmed in a hospital population.

Methods. Between 1987 and 2004, 204 patients with NSCLC received MIP in our institution. Patients treated in and off trials received the same combination of cisplatin $\left(50 \mathrm{mg} / \mathrm{m}^{2}\right)$, ifosfamide $\left(3 \mathrm{~g} / \mathrm{m}^{2}\right)$ and mitomycin $\mathrm{C}(6$ $\mathrm{mg} / \mathrm{m}^{2}$ ) every three weeks and were staged and followed in a similar way.

Results. Response rates for patients treated in or out- side trials were $36.8 \%$ and $40.7 \%$, respectively. After multiple logistic regressions, the only statistically significant factor predicting objective response was stage. The median survival time was $\mathbf{5 4 . 6}$ and $\mathbf{4 3 . 7}$ weeks respectively for patients treated in and outside trials. In multivariate analysis, four factors were statistically significantly associated with better survival: good performance status $(p=0.003)$, normal LDH value $(p<0.001)$, early stage $(p=0.01)$ and active smoking $(\mathbf{p}=\mathbf{0 . 0 3})$.

Conclusion. Participation in a clinical trial was not associated with a significant difference in efficacy. This implementation study thus confirms the activity of the MIP regimen when used in the routine management of patients with NSCLC.

Monaldi Arch Chest Dis 2005; 63: 4, 184-192.

Keywords: Chemotherapy, clinical trial, implementation, non-small cell lung cancer.

1 Department of Intensive Care Unit and Thoracic Oncology, Institut Jules Bordet, Brussels

2 Department of Pneumology, CHU Saint-Pierre, Brussels, Belgium.

Correspondence: Dr Thierry Berghmans; Institut Jules Bordet; Rue Héger-Bordet, 1; Bruxelles 1000; Belgium; e-mail: thierry. berghmans@bordet.be

\section{Introduction}

Non-small cell lung carcinomas (NSCLC) account for $80 \%$ of lung cancer, and it is regarded as one of the most aggressive and life-threatening cancers worldwide. Cisplatin-containing chemotherapy has demonstrated its positive impact on survival in advanced and metastatic NSCLC [1]. Ifosfamide, mitomycin $\mathrm{C}$ and other active drugs [2], as well as vindesine, vinblastine, gemcitabine, vinorelbine, paclitaxel and docetaxel have been tested in various phase II and III clinical trials. There are some discussions about the optimal number of agents to be added to cisplatin. No survival difference was found in a recent meta-analysis when comparing two and three-drugs regimens [3]. However, in these randomised comparisons, doses of the two-drug regimens were frequently reduced when a third drug was added, precluding firm conclusions. Furthermore, it is difficult to make any meaningful results aggregation between first generation drugs only and combinations including second-generation drugs.

In 1988, Cullen et al published a phase II study demonstrating the activity of the MIP regimen (mitomycin $6 \mathrm{mg} / \mathrm{m}^{2}$, ifosfamide $3 \mathrm{~g} / \mathrm{m}^{2}$, cisplatin 50 $\mathrm{mg} / \mathrm{m}^{2}$ ) in unresectable NSCLC [4]. They observed a response rate of $56 \%$. These results were reproduced by other authors in the same population [5-13], although the doses of cisplatin were increased until $120 \mathrm{mg} / \mathrm{m}^{2}$ in some studies. The use of MIP was extended to unresectable stage III NSCLC, in association with radiotherapy $[11,14,15]$ and to induction treatment before surgery [16-18].

Inclusion in clinical trials is considered in the oncology community as a way of offering the best chance for cancer patients. Some associations such as the American Federation of Clinical Oncologic Societies considered this policy as the best treatment option [19]. Recently, Peppercorn et al reviewed the literature about outcome of cancer patients included or not in clinical trials. They concluded that there were not sufficient data to [20] support the belief that enrolment in clinical trials leads to improved outcome. They also claimed that "strategies to control for potential confounding factors were inconsistent and frequently inadequate". Implementation studies need to be performed to answer this question. They consist in assessing the effectiveness of treatments, initially developed in experimental protocols, in general patients' populations. Such a work was recently published demonstrating the usefulness of second-line docetaxel in NSCLC treated in 
routine practice [21]. The authors prospectively collected the patients treated with docetaxel 100 $\mathrm{mg} / \mathrm{m}^{2}$. They confirmed the results of the published randomised trials with a response rate of $7 \%$ and median survival of 9 months. The aims of the present study were to determine response rate and survival after first-line MIP chemotherapy in a single centre unselected NSCLC population and to compare outcome between patients included in clinical trials and those treated outside investigational protocols.

\section{Patients and methods}

All consecutive patients with lung cancer treated at the Institut Jules Bordet, an oncologic cancer institute, were recorded in our database, from which we retrieved those with NSCLC treated by MIP as first-line chemotherapy. During the study period, four protocols of the European Lung Cancer Working Party (ELCWP) were activated. Two were developed for stage III NSCLC comparing chemotherapy versus chemotherapy followed by radiotherapy [14] or assessing the role of increased dose chemotherapy before thoracic radiotherapy [15]. Increased dose chemotherapy was also evaluated in metastatic NSCLC [13]. The fourth ongoing protocol compare MIP to a combination of cisplatin, gemcitabine and vinorelbine as induction treatment in resectable NSCLC (22). Overall, the MIP regimen was similar. Patients treated outside the protocols with MIP received the same chemotherapy in terms of dosage and way of administration.

The MIP regimen consisted of cisplatin (50 $\left.\mathrm{mg} / \mathrm{m}^{2}\right)$, mitomycin C $\left(6 \mathrm{mg} / \mathrm{m}^{2}\right)$ and ifosfamide (3 $\mathrm{g} / \mathrm{m}^{2}$ ) with mesna (uremitexan) rescue, as initially described by Cullen et al (4). The following dose adaptation plan was used during the trials and applied to patients treated outside clinical trials. Courses were repeated every 3 to 4 weeks, as soon as haematological (WBC > 4000/. $\mathrm{mm}^{3}$ and

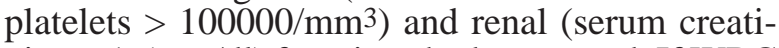
nine $<1.5 \mathrm{mg} / \mathrm{dl}$ ) functions had recovered. If WBC nadir was $<1000 / \mathrm{mm}^{3}$ and/or platelet nadir < $25000 / \mathrm{mm}^{3}$, ifosfamide and mitomycin $\mathrm{C}$ dosage were for the following course reduced to $75 \%$. If serum creatinine peak increased between 1.5 and $3.0 \mathrm{mg} / \mathrm{dl}$, cisplatin dosage was reduced to $50 \%$. If it was $>3.0 \mathrm{mg} / \mathrm{dl}$, cisplatin was stopped. If serum creatinine was not in the normal range on day 21 , cisplatin was omitted.

Work-ups performed before, during and after treatment completion were similar whether or not the patient was included in a study protocol. The initial work-up consisted of a complete history and physical examination with weight, height and surface area measurements; recording of performance status; bronchoscopy with biopsy, chest X-ray and CT scan; bone isotopic scan with X-ray of suspected lesions, eventually replaced by PET scan; liver and adrenals CT scan or echography; brain CT scan or MRI; blood chemistries including complete blood cell count, electrolytes, serum creatinine, and liver function tests; ECG and pulmonary function tests. Blood chemistries, chest X-ray and clinical examination were repeated before each new course. Restaging with all the tests performed during the initial work-up was repeated after every three courses of chemotherapy. After treatment discontinuation, patients were examined with biological tests (as initially performed) and chest Xray every 2 months for the first 6 months and thereafter every 3 months.

Complete remission (CR) was defined as the disappearance of all signs of disease. Partial response (PR), in measurable disease, was defined as a $50 \%$ or greater decrease of the total tumour load, without the appearance of new lesions or progression of any lesion. The tumour load was estimated as the tumour area calculated by the multiplication of the longest diameter by the greatest perpendicular diameter. In assessable disease, PR was defined as an estimated decrease in tumour size of $50 \%$ or more. Progression (PG) was considered to be an increase of greater than $25 \%$ in one or more measurable or assessable lesions or the appearance of a new lesion. All other circumstances were classified as no change (NC). Patients with early death (ED) due to PG before evaluation, those with toxic death due to chemotherapy, or those with early chemotherapy stopping for toxicity were considered as treatment failures and were considered as assessable for response.

Survival was measured from the date of diagnosis until date of death, last date known to be alive or date of analysis (May 1, 2004). Survival distributions were estimated by the Kaplan-Meier method. The log-rank test was used to compare survival distributions. $P$ values (two-tailed) for testing the null hypothesis of the equality of proportions were calculated using a $\chi^{2}$ test. Multivariate analyses for prognostic factors were performed by adjusting the data with Cox models for duration of survival and logistic regression models for objective response. All variables with a $p$ value less or equal to 0.2 in univariate analysis were included in a multivariate model. A $p$ value $<0.05$ was considered as statistically significant. All statistical tests were performed using the software Statistica $^{\circledR}$ (Statsoft, Tulsa, USA).

\section{Results}

From January 1987 to January 2004, 209 patients were treated by MIP. Five patients received chemotherapy before MIP administration and were further excluded from the analysis, leaving $204 \mathrm{el}-$ igible patients. The patients' characteristics are reported in table 1. Median age was 63 years (range 32-79 years). The majority of the patients presented with stage III (53\%) or IV (37\%) disease. There were 78 patients $(38.2 \%)$ treated inside ELCWP protocols, with no difference for characteristics in comparison to those treated outside the trials, except for performance status (PS) and stage (table $1)$. There were more patients with poor PS $(<60)$ or metastatic disease in the cohort treated outside the trials. 


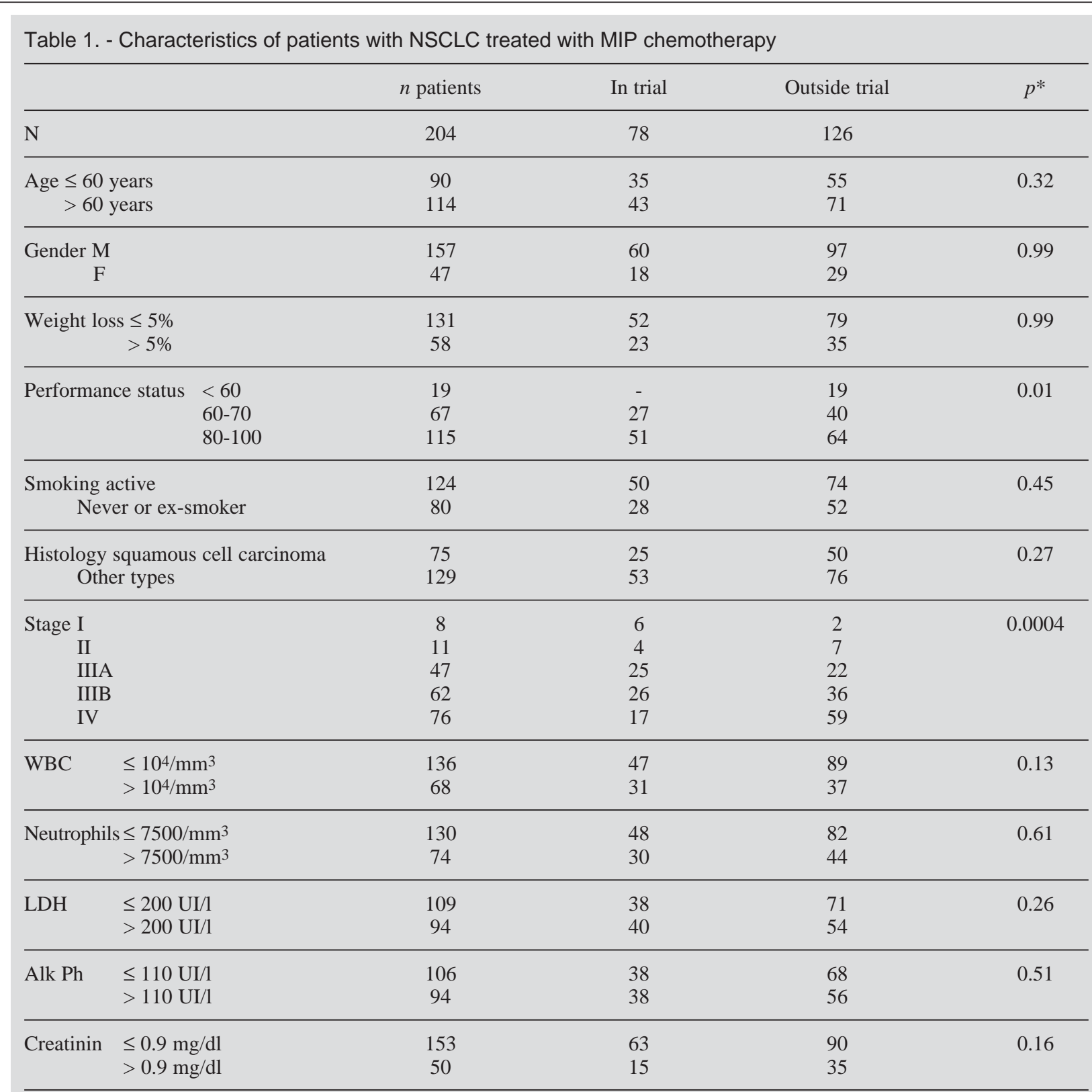

$p$ value for statistical comparison between patients included or not in protocols.

$\mathrm{WBC}=$ white blood cell count.

Patients included in trials were treated with chemotherapy alone in 34 cases. The other 44 patients received, after MIP chemotherapy, thoracic radiotherapy $(n=31)$, surgery $(n=10)$ or both $(n$ $=3$ ). The respective numbers for patients treated who were excluded from the trials were $95,20,9$ and 2 patients. The median number of MIP cycles administered was 3 , whether the patients were included in or excluded from trials, with a total number of 660 courses. 165 patients received at least 3 MIP courses and 35 received 6 or more. The overall response rate to first-line MIP in 194 assessable patients was $39.2 \%$, for patients treated in or outside protocols, respective values of $36.8 \%$ and $40.7 \%$. Detailed response rates are described in table 2 .

Five toxic deaths related to first-line MIP chemotherapy occurred, all of which were among patients treated outside the trial with poor performance status $(<60)$ and/or advanced disease (stages IIIB or IV). Nevertheless, when we combined toxic deaths and treatment interruption for high toxicity, we did not observe anymore statistically significant differences between patients included in the trials $(3.8 \%)$ and those excluded from the trials $(4.8 \%)(\mathrm{p}=0.76)$.

150 patients progressed after first-line therapy, including 62 and 88 treated in and outside the trial. In 46 cases, symptomatic treatment only was offered, without any difference between those included in the trial (17 cases) and those patients excluded from trial $(29$ cases $)(p=0.47)$. Chemotherapy alone or in combination was given to 52 patients (25 included in trial and 27 who were excluded from the trial), of whom 15 received MIP. The type of second-line chemotherapy, cisplatin or 
Table 2. - Response rate to MIP chemotherapy

\begin{tabular}{|c|c|c|c|c|c|c|}
\hline & Total & I & II & IIIA & IIIB & IV \\
\hline Number & 204 & 8 & 11 & 47 & 62 & 76 \\
\hline $\mathrm{CR}$ & 1 & - & - & 1 & - & - \\
\hline PR & 75 & 6 & 6 & 18 & 27 & 18 \\
\hline $\mathrm{NC}$ & 55 & 1 & 5 & 14 & 15 & 20 \\
\hline PD & 51 & - & - & 10 & 11 & 30 \\
\hline Toxic death & 5 & - & - & - & 2 & 3 \\
\hline Early death by cancer & 3 & - & - & - & 2 & 1 \\
\hline High toxicity & 4 & 1 & - & 2 & - & 1 \\
\hline Intercurrent death not related to treatment or cancer & 2 & - & - & - & 2 & - \\
\hline Unassessable & 8 & - & - & 2 & 3 & 3 \\
\hline ORR & $39.2 \%$ & $75.0 \%$ & $54.5 \%$ & $42.2 \%$ & $45.8 \%$ & $24.7 \%$ \\
\hline ORR in patients included in protocols & $36.8 \%$ & $83.3 \%$ & $75.0 \%$ & $28.0 \%$ & $44.0 \%$ & $12.5 \%$ \\
\hline ORR in patients not included in protocols & $40.7 \%$ & $50.0 \%$ & $42.9 \%$ & $60.0 \%$ & $50.0 \%$ & $28.1 \%$ \\
\hline
\end{tabular}

$\mathrm{CR}=$ complete remission; $\mathrm{NC}=$ no change $\mathrm{ORR}=$ objective response rate; $\mathrm{PD}=$ progressive disease $\mathrm{PR}=$ partial remission .

gemcitabine or taxanes based regimens, was similar for patients whether or not they were initially included in clinical trials. Four partial responses were observed among 42 assessable patients $(9.5 \%)$. Other patients were treated with surgery (n $=3)$, radiotherapy $(n=47)$ or skin lesion ablation $(\mathrm{n}=1)$.

Univariate analysis for potential prognostic factors for response was performed in the 194 assessable patients (table 3 ). Good performance status and early stage were statistically associated with better response rates. These two factors in addition with alkaline phosphatases and white blood cell count were included in a multiple logistic regression analysis (table 4). Only stage was found an independent prognostic factor for response in multivariate analysis $(\mathrm{p}=0.004)$.

At the time of the analysis, 32 patients were alive, 163 were dead and 9 were lost to follow-up. The respective values for patients treated in and excluded from trials were 12, 63 and 3 and 20, 100 and 6. Cancer was the cause of death in 102 cases, related to treatment in 7 patients, of which 5 occurred during first-line MIP chemotherapy, and was not related to treatment or cancer in 12 others. The five toxic deaths related to first-line MIP occurred among patients treated excluded from trials. In the last 42 cases, the direct cause of death was not known. Overall, the median survival time (MST) was 48.6 weeks. MST was in stages I, II, IIIA, IIIB and IV of 101.6 (3 deaths), 84 (6 deaths), 52.9 (40 deaths), 62.9 (49 deaths) and 34.1 weeks (65 deaths), respectively. Univariate prognostic factor analysis for survival is shown in table 5. Active smoking $(p=0.05)$, minimal weight loss $(p=$ $0.02)$, good performance status $(p<0.001)$, normal LDH value $(p<0.001)$ and early stage $(p<0.001)$ were significantly associated with better outcome. These factors as well as protocol inclusion and alkaline phosphatases level were included in a multivariate Cox model analysis (table 6). Four factors were significantly associated with better survival: good performance status $(p=0.003)$, normal LDH level $(p<0.001)$, early stage $(p=0.01)$ and active smoking $(p=0.03)$. Inclusion in a clinical trial had no impact on survival. Because of missing data, a second model was constructed excluding weight loss (table 6) with similar results.

\section{Discussion}

In this retrospective analysis, we implemented the role of the combination of cisplatin, ifosfamide and mitomycin (MIP regimen) for NSCLC. We observed an overall response rate of $39 \%$, equivalent to those reported in the literature. We did not find any significant difference between patients whether or not they were included in clinical trials in terms of response rate or survival. Factors significantly associated with survival were stage, performance status, LDH level and smoking status. The disease stage was the only predictor of response to MIP chemotherapy in NSCLC.

Inclusion in clinical trials is frequently considered to offer a survival advantage for the patient. 


\begin{tabular}{|c|c|c|c|}
\hline & Response & No response & $p$ \\
\hline \multirow{2}{*}{$\begin{aligned} \text { Age } & \leq 60 \text { years } \\
& >60 \text { years }\end{aligned}$} & 30 & 55 & 0.33 \\
\hline & 46 & 63 & \\
\hline Gender M & 57 & 94 & 0.45 \\
\hline $\mathrm{F}$ & 19 & 24 & \\
\hline \multirow{2}{*}{$\begin{array}{l}\text { Smoking active } \\
\text { no }+ \text { ex }\end{array}$} & 45 & 74 & 0.62 \\
\hline & 31 & 44 & \\
\hline \multirow{2}{*}{$\begin{aligned} \text { Weight loss } & \leq 5 \% \\
& >5 \%\end{aligned}$} & 51 & 73 & 0.41 \\
\hline & 19 & 36 & \\
\hline \multirow{3}{*}{$\begin{aligned} \text { PS } & <60 \\
& 60-70 \\
& 80-100\end{aligned}$} & 2 & 15 & $<0.001$ \\
\hline & 24 & 43 & \\
\hline & 49 & 58 & \\
\hline Protocol inclusion yes & 28 & 48 & 0.59 \\
\hline no & 48 & 70 & \\
\hline \multirow{2}{*}{$\begin{array}{l}\text { Histology squamous } \\
\text { non squamous }\end{array}$} & 31 & 42 & 0.47 \\
\hline & 45 & 76 & \\
\hline Stage I/II & 12 & 7 & 0.001 \\
\hline III & 46 & 58 & \\
\hline IV & 18 & 55 & \\
\hline \multirow{2}{*}{$\begin{aligned} \text { Creatinin } & \leq 0.9 \mathrm{mg} / \mathrm{dl} \\
& >0.9 \mathrm{mg} / \mathrm{dl}\end{aligned}$} & 59 & 85 & 0.44 \\
\hline & 17 & 32 & \\
\hline$\leq 110 \mathrm{UI} / 1$ & 45 & 56 & 0.11 \\
\hline > $110 \mathrm{UI} / 1$ & 30 & 60 & \\
\hline$\leq 200 \mathrm{UI} / 1$ & 45 & 60 & 0.28 \\
\hline$>200 \mathrm{UI} / 1$ & 31 & 57 & \\
\hline WBC & 55 & 72 & 0.10 \\
\hline$>104 / \mathrm{mm}^{3}$ & 21 & 46 & \\
\hline \multirow{2}{*}{$\begin{aligned} \text { Neutrophils } & \leq 7500 / \mathrm{mm}^{3} \\
& >7500 / \mathrm{mm}^{3}\end{aligned}$} & 52 & 71 & 0.24 \\
\hline & 24 & 47 & \\
\hline
\end{tabular}

Alk $\mathrm{Ph}=$ alkaline phosphatase $; \mathrm{PS}=$ performance status; $\mathrm{WBC}=$ white blood cell count .

\begin{tabular}{lcc} 
Table 4. - Multiple logistic regression analysis of \\
prognostic factors for response \\
\hline & $\beta$ value & $p$ \\
\hline Stage & 0.22 & 0.004 \\
\hline Performance status & -0.11 & 0.14 \\
\hline Alkaline phosphatase & 0.07 & 0.33 \\
\hline White blood cell count & 0.11 & 0.13 \\
\hline
\end{tabular}

Potential explanations are better follow-up or better access to aggressive, resuscitating or secondline treatments. Based on a literature review, Peppercorn et al found no clear advantage for the patient to be included in experimental studies [20]. In the European Union, there is some interest in as-

sessing the efficacy of treatments in general unselected populations, in comparison to those obtained in trials. We decided to perform such an implementation study in our patients with NSCLC treated by MIP.

The MIP regimen remains one of the standard chemotherapy in NSCLC, whatever the stage of the disease $[11,18]$. The ELCWP has been performed over the last fifteen years in 3 randomised trials in advanced [14, 15] or metastatic [13] NSCLC. In addition, we currently perform a randomised trial of neo-adjuvant chemotherapy in operable NSCLC, comparing MIP to a second generation based chemotherapy [22]. Patients treated outside the ELCWP protocols received the MIP regimen in similar modalities (dose, schedule, work-up, follow-up). The cisplatin dosage that we have used has to be discussed. In the initial MIP designed by Cullen [4], cisplatin was administered at a dose of $50 \mathrm{mg} / 2$, every 3 weeks. Other authors 
Table 5. - Univariate analysis of prognostic factors for survival in patients with NSCLC treated with MIP chemotherapy

\begin{tabular}{|c|c|c|c|c|}
\hline & MST (weeks) & $\mathrm{N}$ deaths & $\mathrm{N}$ censored & $p$ \\
\hline \multirow{2}{*}{$\begin{aligned} \text { Age } & \leq 60 \text { years } \\
& >60 \text { years }\end{aligned}$} & 49.7 & 76 & 14 & \multirow[t]{2}{*}{0.82} \\
\hline & 47.4 & 87 & 27 & \\
\hline Gender $\mathrm{M}$ & 46.3 & 123 & 34 & \multirow[t]{2}{*}{0.75} \\
\hline & 57.9 & 40 & 7 & \\
\hline Smoking active & 53.3 & 95 & 29 & \multirow[t]{2}{*}{0.05} \\
\hline Nevere + ex smoker & 40.7 & 68 & 12 & \\
\hline \multirow{2}{*}{$\begin{aligned} \text { Weight loss } & \leq 5 \% \\
& >5 \%\end{aligned}$} & 55.1 & 102 & 29 & \multirow[t]{2}{*}{0.02} \\
\hline & 35.9 & 50 & 8 & \\
\hline \multirow{3}{*}{$\begin{aligned} \text { PS } & <60 \\
& 60-70 \\
& 80-100\end{aligned}$} & 20.7 & 18 & 1 & \multirow[t]{3}{*}{$<0.001$} \\
\hline & 35.6 & 59 & 8 & \\
\hline & 68.7 & 83 & 32 & \\
\hline Protocol inclusion yes & 54.6 & 63 & 15 & \multirow[t]{2}{*}{0.06} \\
\hline no & 43.7 & 100 & 26 & \\
\hline \multirow{2}{*}{$\begin{array}{l}\text { Histology squamous cell carcinoma } \\
\text { Other types }\end{array}$} & 59.0 & 57 & 18 & \multirow[t]{2}{*}{0.66} \\
\hline & 45.9 & 106 & 23 & \\
\hline \multirow{3}{*}{$\begin{array}{c}\text { Stage I/II } \\
\text { III } \\
\text { IV }\end{array}$} & 95.0 & 9 & 10 & \multirow[t]{3}{*}{$<0.001$} \\
\hline & 59.1 & 89 & 20 & \\
\hline & 34.1 & 65 & 11 & \\
\hline \multirow{2}{*}{$\begin{aligned} \text { Creatinin } & \leq 0.9 \mathrm{mg} / \mathrm{dl} \\
& >0.9 \mathrm{mg} / \mathrm{dl}\end{aligned}$} & 50.0 & 123 & 30 & \multirow[t]{2}{*}{0.99} \\
\hline & 43.0 & 39 & 11 & \\
\hline$\leq 110 \mathrm{UI} / 1$ & 53.7 & 83 & 23 & \multirow[t]{2}{*}{0.10} \\
\hline$>110 \mathrm{UI} / 1$ & 42.9 & 79 & 15 & \\
\hline$\leq 200 \mathrm{UI} / 1$ & 68.0 & 81 & 28 & \multirow[t]{2}{*}{$<0.001$} \\
\hline$>200 \mathrm{UI} / 1$ & 34.7 & 82 & 12 & \\
\hline$\leq 10^{4} / \mathrm{mm}^{3}$ & 46.9 & 107 & 29 & \multirow[t]{2}{*}{0.71} \\
\hline$>10^{4} / \mathrm{mm}^{3}$ & 55.3 & 56 & 12 & \\
\hline \multirow{2}{*}{$\begin{aligned} \text { Neutrophils } & \leq 7500 / \mathrm{mm}^{3} \\
& >7500 / \mathrm{mm}^{3}\end{aligned}$} & 49.0 & 101 & 29 & \multirow[t]{2}{*}{0.65} \\
\hline & 46.7 & 62 & 12 & \\
\hline
\end{tabular}

Alk $\mathrm{Ph}=$ alkaline phosphatase; $\mathrm{PS}=$ performance status; $\mathrm{WBC}=$ white blood cell count; $\mathrm{MST}=$ Medial Survival Time.

have increased cisplatin dosage up to $120 \mathrm{mg} / \mathrm{m}^{2}$ $[7,9]$, although no better response rate was observed with higher dose of cisplatin. Furthermore, there has been no survival benefit associated with high dose cisplatin in randomised studies [23-27] although more chronic toxicity (renal, auditive or neurologic) was found [25]. Based on these considerations, we decided to use systematically the Cullen's MIP regimen for patients treated outside clinical trials.

The response rate in our series, whether or not the patient was included in an experimental protocol, was similar to those reported in the literature (table 7). If the comparison is restricted to trials including a number of patients equivalent to our study, the response rate does not differ from the $39 \%$ of our implementation study, ranging from $26 \%$ in stage IIIB/IV [8] to $64 \%$ in operable disease [18]. A multiple logistic regression analysis showed that the only statistically significant prog- nostic factor for objective response was disease stage. Indeed, in the literature, the response rate is lower in metastatic disease [11] than in inoperable locoregional [11] or surgical stages [16-18]. Also, inclusion in a clinical trial had no impact on survival in patients receiving MIP chemotherapy. After multivariate analysis, we found 4 independent prognostic factors for survival: good performance status, normal LDH level, early stage and active smoking. Disease stage, performance status and $\mathrm{LDH}$ are well known prognostic factors for survival [28]. In a previous study including 1052 patients treated in ELCWP trials, we also found that stage and performance status were independent statistically significant factors for survival [29]. In the present report, although more patients with poor performance status were treated 'off protocol', inclusion in a clinical trial had no statistically significant impact on survival. One potential explanation is that these poor PS patients received the same 


\begin{tabular}{|c|c|c|}
\hline & $\beta$ value & $p$ \\
\hline \multicolumn{3}{|c|}{$1^{\text {st }}$ model ( $\mathrm{n}=182$ observations $)$} \\
\hline Performance status & -0.46 & 0.003 \\
\hline LDH level & 0.64 & $<0.001$ \\
\hline Stage & 0.39 & 0.01 \\
\hline Smoking status & 0.36 & 0.03 \\
\hline \multicolumn{3}{|c|}{$2^{\text {nd }}$ model ( $\mathrm{n}=196$ observations $)$} \\
\hline Performance status & -0.52 & $<0.001$ \\
\hline LDH level & 0.56 & $<0.001$ \\
\hline Stage & 0.40 & 0.009 \\
\hline Smoking status & 0.40 & 0.01 \\
\hline \multicolumn{3}{|c|}{$\begin{array}{l}1 \text { st model including weight loss, performance status, LDH, } \\
\text { Protocol inclusion, Alkaline phosphatases level, Stage, } \\
\text { smoking status; the } 2^{\text {nd }} \text { model includes the same variables } \\
\text { except weight loss. }\end{array}$} \\
\hline
\end{tabular}

dosage and schedule of chemotherapy than those treated according to experimental protocols. In recently published literature, smoking cessation is reported to be associated with better survival [30]. In the present study, we observed the opposite. We do not have any meaningful explanation for this discrepancy, except the methodology. Our study is ret- rospective, therefore this finding needs confirmation in a well designed prospective study.

To implement results of randomised trials in routine practice, outside of the therapeutic effect on survival, treatment toxicity and the impact on quality of life in general populations are two main end-points to be assessed. Unfortunately, we did not have enough information to directly perform such an analysis. When we looked at toxic deaths due to MIP chemotherapy, all occurred in patients treated outside the trials. However, these patients had poor performance status $(<60)$ and presented with advanced disease (stages IIIB or IV), that are poor prognostic factors for survival. Nevertheless, when we combined toxic deaths and treatment interruption for high toxicity, we did not observe anymore statistically significant differences between those included in the trials $(3.8 \%)$ and those patients outside the trial $(4.8 \%)(\mathrm{p}=0.76)$. Lastly, there was no difference in the median number of cycles administered, suggesting that MIP was equally tolerated among patients treated in or outside trials.

We tried to avoid potential bias due to the retrospective design of our study. There was no patient selection because all the patients with lung cancer treated in our institution are prospectively included in a database in which the majority of the data is prospectively registered. Patients not included in study protocols and able to receive MIP were treated in the same way than patients included in the ELCWP trials, with the same chemotherapy dosage and schedule of administration. The initial and evaluation work-ups, follow-up and assessment criteria as well as dose adaptation plans in patients treated outside trials were those applied

Table 7. Response rates in studies assessing the Cullen's MIP regimen in patients with NSCLC

\begin{tabular}{|c|c|c|c|c|}
\hline References & Type of study & $\mathrm{N}$ patients & Disease stage & ORR \\
\hline Cullen, 1988 [4] & Phase II & 66 & $\mathrm{LD} / \mathrm{ED}$ & $56 \%$ \\
\hline Cullen, 1999 [11] & Phase III & 223 & LD & $54 \%$ \\
\hline Cullen, 1999 [11] & Phase III & 175 & ED & $32 \%$ \\
\hline Currie, 1990 [5] & Phase II & 45 & $\mathrm{LD} / \mathrm{ED}$ & $40 \%$ \\
\hline Sculier, 1999 [14] & Phase III & 462 & IIIA/IIIB & $38 \%$ \\
\hline Sculier, 2001 [13] & Phase III & 297 & IIIB/IV & $27 \%$ \\
\hline Sculier, 2004 [15] & Phase III & 176 & IIIA/IIIB & $35 \%$ \\
\hline Han, 1998 [12] & Phase II & 38 & IIIB/IV & $39 \%$ \\
\hline Rosell, 1999 [16] & Phase III & 30 & Operable IIIA & $53 \%$ \\
\hline Felip, 2000 [17] & Phase III & 27 & Operable IIIA & $30 \%$ \\
\hline Berghmans, 2004 & Implementation & $\begin{array}{c}194 \\
76 \text { (in trial) } \\
118 \text { (out of trial) }\end{array}$ & I-IV & $\begin{array}{l}39 \% \\
37 \% \\
41 \%\end{array}$ \\
\hline
\end{tabular}

$\mathrm{ED}=$ extensive disease $\mathrm{LD}=$ limited disease $; \mathrm{ORR}=$ objective response rate 
in the ELCWP protocols. As for patients treated in clinical trials, patients excluded from the trials were offered second-line chemotherapy in cases of progression. There were two statistically significant differences between patients included or not in protocols: disease stage and performance status. More patients with early stage NSCLC were included in trials because neo-adjuvant chemotherapy was only recently recognised as potentially useful in this setting $[16,18]$ and was not a standard of care during the period considered for inclusion in our implementation study. There were less patients with stage IV NSCLC included in protocols, partly because patients with poor performance status $(<60)$, which is a common exclusion criterion in ELCWP trials, could not be included in experimental protocols.

Implementation studies are of particular importance when guidelines have to be proposed. Clinical trials have poor external validity due to the patients' selection and applicability to general patients population has to be shown. Implementation studies are a way of obtaining information on the efficacy of treatment in routine practice. For example, the European Union proposed the AGREE (Appraisal of Guidelines for Research and Evaluation instrument) instrument in order to assess published guidelines (www.agreecollaboration.org). The item 7 asks for complementary validation of guidelines in "unselected" target population. Implementation studies, as presently performed, can help to answer this question.

In conclusion, our implementation study confirms that patients with NSCLC treated with MIP as first-line chemotherapy presented with similar chance for objective response and prognosis whether or not they were included in clinical trials. This could be explained by the fact that all patients were treated and followed in the same way. In routine practice, the MIP regimen can be considered as a standard treatment, alone or in association with surgery or radiotherapy, for the treatment of patients with NSCLC who cannot be included in experimental protocols. The MIP regimen can be proposed as standard chemotherapy in future guidelines for the treatment of patients with NSCLC. These results need to be integrated into clinical practice taking into account the results of recent randomised trials which found similar results for two- and three-drugs combinations, including second-generation agents [3, 31-33]. For equivalent response rates and survival, costs of these new regimens must be compared to cheaper chemotherapy regimens like MIP. Furthermore, the central role of cisplatin is debated, considering that some combinations with second-generation drugs without cisplatin demonstrate similar results than cisplatin-based regimens [34-37].

\section{References}

1. Chemotherapy in non-small cell lung cancer: a metaanalysis using updated data on individual patients from 52 randomised clinical trials. Non-small Cell Lung Cancer Collaborative Group. BMJ 1995; 311: 899-909.
2. Donnadieu N, Paesmans M, Sculier JP. [Chemotherapy of non-small cell bronchial cancers. Meta-analysis of the literature as a function of the extent of the disease]. Rev Mal Respir 1991; 8: 197-204.

3. Delbaldo C, Michiels S, Syz N, Soria JC, Le Chevalier T, Pignon JP. Benefits of adding a drug to a singleagent or a 2-agent chemotherapy regimen in advanced non-small-cell lung cancer: a meta-analysis. JAMA 2004; 292: 470-484.

4. Cullen MH, Joshi R, Chetiyawardana AD, Woodroffe CM. Mitomycin, ifosfamide and cis-platin in non-small cell lung cancer: treatment good enough to compare. $\mathrm{Br}$ J Cancer 1988; 58: 359-61.

5. Currie DC, Miles DW, Drake JS, et al. Mitomycin, ifosfamide and cisplatin in non-small-cell lung cancer. Cancer Chemother Pharmacol 1990; 25: 380-381.

6. Mariani GL, Pennucci MC, Addamo G, Venturini M, Ardizzoni A, Rosso R. A pilot study of mitomycin, ifosfamide and cisplatin as outpatient combination chemotherapy for advanced non-small cell lung cancer. Tumori 1991; 77: 511-13.

7. Crino L, Corgna E, Porrozzi S, et al. A better therapeutic profile for the combination of mitomycin-C, ifosfamide and cisplatin (MIC) in advanced non-small-cell lung cancer: a useful dose-schedule modification. Ann Oncol 1997; 8: 709-11.

8. Crino L, Scagliotti GV, Ricci S, et al. Gemcitabine and cisplatin versus mitomycin, ifosfamide, and cisplatin in advanced non-small-cell lung cancer: A randomized phase III study of the Italian Lung Cancer Project. $J$ Clin Oncol 1999; 17: 3522-30.

9. Crino L, Clerici M, Figoli F, et al. Chemotherapy of advanced non-small-cell lung cancer: a comparison of three active regimens. A randomized trial of the Italian Oncology Group for Clinical Research (G.O.I.R.C.). Ann Oncol 1995; 6: 347-53.

10. Urban T, Bedin A, Baud M, Chouaid C, Febvre M, Lebeau B. Efficacy and toxicity of mitomycin, ifosfamide, and cisplatin (MIP) in patients with inoperable non-small cell lung cancer. Lung Cancer 1996; 14: 109-17.

11. Cullen MH, Billingham LJ, Woodroffe CM, et al. Mitomycin, ifosfamide, and cisplatin in unresectable nonsmall-cell lung cancer: effects on survival and quality of life. J Clin Oncol 1999; 17: 3188-94.

12. Han JY, Kim HK, Choi BG, Moon H, Hong YS, Lee KS. Quality of life (QOL) assessment of MIP (mitomycin, ifosfamide and cisplatin) chemotherapy in advanced non-small cell lung cancers (NSCLC). Jpn J Clin Oncol 1998; 28: 749-53.

13. Sculier JP, Lafitte JJ, Paesmans M, et al. Phase III randomized trial comparing moderate-dose cisplatin to combined cisplatin and carboplatin in addition to mitomycin and ifosfamide in patients with stage IV nonsmall-cell lung cancer. Br J Cancer 2000; 83: 1128-35.

14. Sculier JP, Paesmans M, Lafitte JJ, et al. A randomised phase III trial comparing consolidation treatment with further chemotherapy to chest irradiation in patients with initially unresectable locoregional non-small-cell lung cancer responding to induction chemotherapy. European Lung Cancer Working Party. Ann Oncol 1999; 10: 295-303.

15. Sculier JP, Lafitte JJ, Berghmans T, et al. A phase III randomised study comparing two different dose-intensity regimens as induction chemotherapy followed by thoracic irradiation in patients with advanced locoregional non-small-cell lung cancer. Ann Oncol 2004; 15: 399-409.

16. Rosell R, Gomez-Codina J, Camps C, et al. Preresectional chemotherapy in stage IIIA non-small-cell lung cancer: a 7-year assessment of a randomized controlled trial. Lung Cancer 1999; 26: 7-14. 
17. Felip E, Rosell R, Alberola V, et al. Preoperative highdose cisplatin versus moderate-dose cisplatin combined with ifosfamide and mitomycin in stage IIIA (N2) non small-cell lung cancer: results of a randomized multicenter trial. Clin Lung Cancer 2000; 1: 287-93.

18. Depierre A, Milleron B, Moro-Sibilot D, et al. Preoperative chemotherapy followed by surgery compared with primary surgery in resectable stage I (except T1N0), II, and IIIa non-small-cell lung cancer. J Clin Oncol 2002; 20: 247-53.

19. Access to quality cancer care: consensus statement. American Federation of Clinical Oncologic Societies. $J$ Clin Oncol 1998; 16: 1628-30.

20. Peppercorn JM, Weeks JC, Cook EF, Joffe S. Comparison of outcomes in cancer patients treated within and outside clinical trials: conceptual framework and structured review. Lancet 2004; 363: 263-70.

21. Sumpter K, Harper-Wynne C, Yeoh C, et al. Is the second line data on the use of docetaxel in non-small cell lung cancer reproducible? Lung Cancer 2004; 43: 369-70.

22. Ph Lothaire, T Berghmans, JJ Lafitte, et al. Resectability after two different chemotherapy regimens: results of the first step of a phase II randomised trial in initially resectable stage I-IIIa non-small cell lung cancer conducted by the European Lung Cancer Working Party. Eur Respir J 22 (suppl 45): 2003.

23. Gralla RJ, Casper ES, Kelsen DP, et al. Cisplatin and vindesine combination chemotherapy for advanced carcinoma of the lung: A randomized trial investigating two dosage schedules. Ann Intern Med 1981; 95: 414-20.

24. Shinkai T, Saijo N, Eguchi K, et al. Cisplatin and vindesine combination chemotherapy for non-small cell lung cancer: a randomized trial comparing two dosages of cisplatin. Jpn J Cancer Res 1986; 77: 782-89.

25. Sculier JP, Klastersky J, Giner V, et al. Phase II randomized trial comparing high-dose cisplatin with moderate-dose cisplatin and carboplatin in patients with advanced non-small-cell lung cancer. European Lung Cancer Working Party. J Clin Oncol 1994; 12: 353-59.

26. Klastersky J, Sculier JP, Ravez P, et al. A randomized study comparing a high and a standard dose of cisplatin in combination with etoposide in the treatment of advanced non-small-cell lung carcinoma. J Clin Oncol 1986; 4: 1780-1786.

27. Gandara DR, Crowley J, Livingston RB, et al. Evaluation of cisplatin intensity in metastatic non-small-cell lung cancer: a phase III study of the Southwest Oncology Group. J Clin Oncol 1993; 11: 873-78.

28. Buccheri G, Ferrigno D. Prognostic factors in lung can- cer: tables and comments. Eur Respir J 1994; 7: 13501364.

29. Paesmans M, Sculier JP, Libert P, et al. Prognostic factors for survival in advanced non-small-cell lung cancer: univariate and multivariate analyses including recursive partitioning and amalgamation algorithms in 1, 052 patients. The European Lung Cancer Working Party. J Clin Oncol 1995; 13: 1221-30.

30. Tammemagi CM, Neslund-Dudas C, Simoff M, Kvale P. Smoking and lung cancer survival: the role of comorbidity and treatment. Chest 2004; 125: 27-37.

31. Alberola V, Camps C, Provencio M, et al. Cisplatin plus gemcitabine versus a cisplatin-based triplet versus nonplatinum sequential doublets in advanced nonsmall-cell lung cancer: a Spanish Lung Cancer Group phase III randomized trial. J Clin Oncol 2003; 21: 3207-13.

32. Comella P, Frasci G, Panza N, et al. Randomized trial comparing cisplatin, gemcitabine, and vinorelbine with either cisplatin and gemcitabine or cisplatin and vinorelbine in advanced non-small-cell lung cancer: interim analysis of a phase III trial of the Southern Italy Cooperative Oncology Group. J Clin Oncol 2000; 18: 1451-57.

33. Souquet PJ, Tan EH, Rodrigues PJ, et al. GLOB-1: a prospective randomised clinical phase III trial comparing vinorelbine-cisplatin with vinorelbine-ifosfamidecisplatin in metastatic non-small-cell lung cancer patients. Ann Oncol 2002; 13: 1853-61.

34. Sculier JP, Lafitte JJ, Lecomte J, et al. A three-arm phase III randomised trial comparing combinations of platinum derivatives, ifosfamide and/or gemcitabine in stage IV non-small-cell lung cancer. Ann Oncol 2002; 13: 874-82.

35. Smit EF, van Meerbeeck JP, Lianes P, et al. Three-arm randomized study of two cisplatin-based regimens and paclitaxel plus gemcitabine in advanced non-small-cell lung cancer: a phase III trial of the European Organization for Research and Treatment of Cancer Lung Cancer Group-EORTC 08975. J Clin Oncol 2003; 21: 3909-17.

36. Kosmidis P, Mylonakis N, Nicolaides C, et al. Paclitaxel plus carboplatin versus gemcitabine plus paclitaxel in advanced non-small-cell lung cancer: a phase III randomized trial. J Clin Oncol 2002; 20: 3578-85.

37. D'Addario G, Pintilie M, Leighl NB, Feld R, Cerny T, Shepherd FA. Platinum-based versus non-platinumbased chemotherapy in advanced non-small-cell lung cancer: a meta-analysis of the published literature. $J$ Clin Oncol 2005; 23: 2926-36.

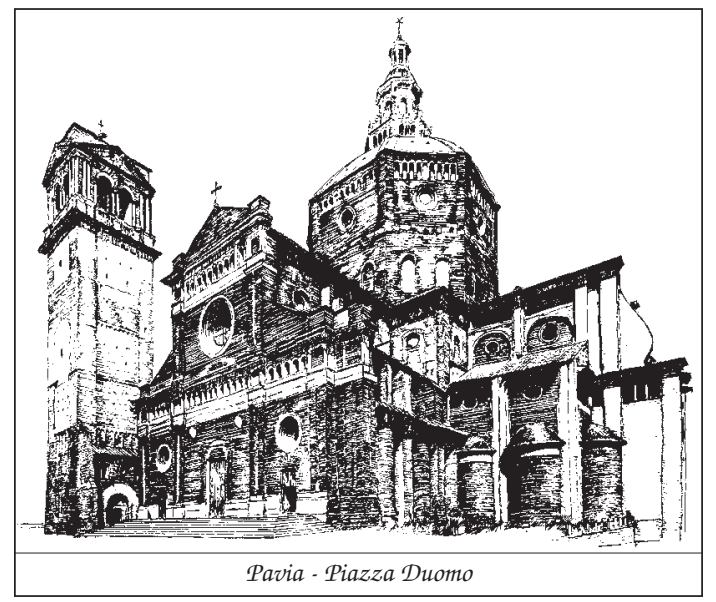

